Article

\title{
Feature Selection as a Time and Cost-Saving Approach for Land Suitability Classification (Case Study of Shavur Plain, Iran)
}

\author{
Saeid Hamzeh ${ }^{1, *}$, Marzieh Mokarram ${ }^{2}$, Azadeh Haratian ${ }^{3}$, Harm Bartholomeus ${ }^{4}$, \\ Arend Ligtenberg ${ }^{4}$ and Arnold K. Bregt ${ }^{4}$ \\ 1 Department of Remote Sensing and GIS, Faculty of Geography, University of Tehran, P.O. Box 14155-6465, \\ Tehran, Iran \\ 2 Department of Range and Watershed, Agriculture College and Natural Resources of Darab, \\ Shiraz University, Shiraz, Iran; m.mokarram@shirazu.ac.ir \\ 3 Department of cognitive science modeling, Institute for Cognitive Science Studies, Tehran, Iran; \\ haratian_a@iricss.org \\ 4 Laboratory of Geo-Information Science and Remote Sensing, Wageningen University, P.O. Box 47, \\ 6700 AA Wageningen, The Netherlands; Harm.Bartholomeus@wur.nl (H.B.); \\ Arend.Ligtenberg@wur.nl (A.L.); arnold.bregt@wur.nl (A.K.B.) \\ * Correspondence: saeid.hamzeh@ut.ac.ir; Tel.: +98-2161113792
}

Academic Editor: Ritaban Dutta

Received: 29 July 2016; Accepted: 30 September 2016; Published: 10 October 2016

\begin{abstract}
Land suitability classification is important in planning and managing sustainable land use. Most approaches to land suitability analysis combine a large number of land and soil parameters, and are time-consuming and costly. In this study, a potentially useful technique (combined feature selection and fuzzy-AHP method) to increase the efficiency of land suitability analysis was presented. To this end, three different feature selection algorithms-random search, best search and genetic methods-were used to determine the most effective parameters for land suitability classification for the cultivation of barely in the Shavur Plain, southwest Iran. Next, land suitability classes were calculated for all methods by using the fuzzy-AHP approach. Salinity (electrical conductivity (EC)), alkalinity (exchangeable sodium percentage (ESP)), wetness and soil texture were selected using the random search method. Gypsum, EC, ESP, and soil texture were selected using both the best search and genetic methods. The result shows a strong agreement between the standard fuzzy-AHP methods and methods presented in this study. The values of Kappa coefficients were 0.82, 0.79 and 0.79 for the random search, best search and genetic methods, respectively, compared with the standard fuzzy-AHP method. Our results indicate that EC, ESP, soil texture and wetness are the most effective features for evaluating land suitability classification for the cultivation of barely in the study area, and uses of these parameters, together with their appropriate weights as obtained from fuzzy-AHP, can perform good results for land suitability classification. So, the combined feature selection presented and the fuzzy-AHP approach has the potential to save time and money for land suitability classification.
\end{abstract}

Keywords: land suitability; fuzzy-AHP; feature selection; random search; genetic method

\section{Introduction}

Land suitability analyses assess the suitability of land for specific uses such as arable farming, irrigated agriculture, forest, urbanization, industry, waste disposal, etc. [1-3].

Agriculture land suitability classification is defined as the process of assessment of land performance for alternative kinds of agriculture activity and crop type [1,4,5]. This activity is vital 
to predict the potential and limitation of land for crop production; the systematic assessment of land and water potential; and to select the best land for the cultivation of a given agricultural product [1,4-7]. In 1976, the Food and Agriculture Organization (FAO) proposed a framework for land suitability classification which allows five classes of suitability (three suitable and two not suitable) for certain crops [1]. Later, the FAO classification model was adapted for use with a wider range of soil and environmental characteristics [8-10]. The geographical information system (GIS) has added a much-needed spatial dimension to land suitability mapping and management, and has become a powerful tool in this regard [11-13]. Different combined GIS and expert systems such as multi-criteria decision analysis [5,14-18], artificial intelligence in geo-computation methods [19-21], visualization methods [22], analytical hierarchy process (AHP) [23,24], fuzzy modeling [25-29] and Fuzzy-AHP methods [30-33] have been widely used for agricultural land suitability classification. In all of these methods, the topography, wetness, salinity (electrical conductivity (EC)), alkalinity (exchangeable sodium percentage (ESP)), soil texture, soil depth, $\mathrm{CaCO}_{3}, \mathrm{pH}\left(\mathrm{H}_{2} \mathrm{O}\right)$ and gypsum are important parameters for the evaluation of land suitability for the cultivation of different crops [34].

Because of the large number of inputs required, determining land suitability through existing approaches is time consuming and costly. Hence, the development of methods that minimize and optimize the input parameters for land suitability analysis is important. One method that shows potential is data mining-based feature selection. The data-mining approach is based on identifying valuable information in an existing database [35]. The first requirement for successful data mining is to identify the most important features through a database [36]. The feature selection methods can be seen as the combination of search approaches for proposing new feature subsets, along with an assessment measure that scores the several feature subsets [37].

Recently, several studies have evaluated feature selection for use in digital soil mapping and classification [38-40]. As such, feature selection could be useful in studies with a large number of input parameters, such as land suitability analyses [41]. However, so far, no study has evaluated this method for land suitability evaluation, with the exception of a conference proceeding paper by Mokarram et al. [41]. Here, we present an extended version of this conference paper, in which we aimed to assess the capabilities of different feature selection algorithms (random search, best search and genetic methods), in combination with fuzzy-AHP, for land suitability classification for the cultivation of barley. In addition, we aimed to determine the most effective parameters for this purpose. The accuracy of the combined feature selection and fuzzy-AHP methods are compared with the standard method of FAO, and the best method and framework for this task was selected and discussed.

\section{Materials and Methods}

\subsection{Study Area}

The study area, Shavur Plain, is located in the Khuzestan province, in southwest Iran, between latitudes $31^{\circ} 00^{\prime} 30^{\prime \prime} \mathrm{N}$ and $32^{\circ} 30^{\prime} 00^{\prime \prime} \mathrm{N}$ and longitudes $48^{\circ} 15^{\prime} 00^{\prime \prime} \mathrm{E}$ and $48^{\circ} 40^{\prime} 40^{\prime \prime} \mathrm{E}$. It has an area of $774 \mathrm{~km}^{2}$ (Figure 1). The area has an arid and semi-arid climate with an average annual precipitation of $266 \mathrm{~mm}$ and annual evaporation from open pans of $2788.3 \mathrm{~mm} \cdot \mathrm{year}^{-1}$.

\subsection{Dataset}

Data used for this study include topography (primary slope, secondary slope and micro-relief), wetness (water table depth), salinity (EC), alkalinity (ESP), soil texture, soil depth, $\mathrm{CaCO}_{3}, \mathrm{pH}$, and gypsum, which were extracted from the land classification report published by the Khuzestan Soil and Water Research Institute in 2009 [42]. These data were collected by sampling 256 points randomly distributed in the study area. A summary of the dataset is shown in Table 1. 


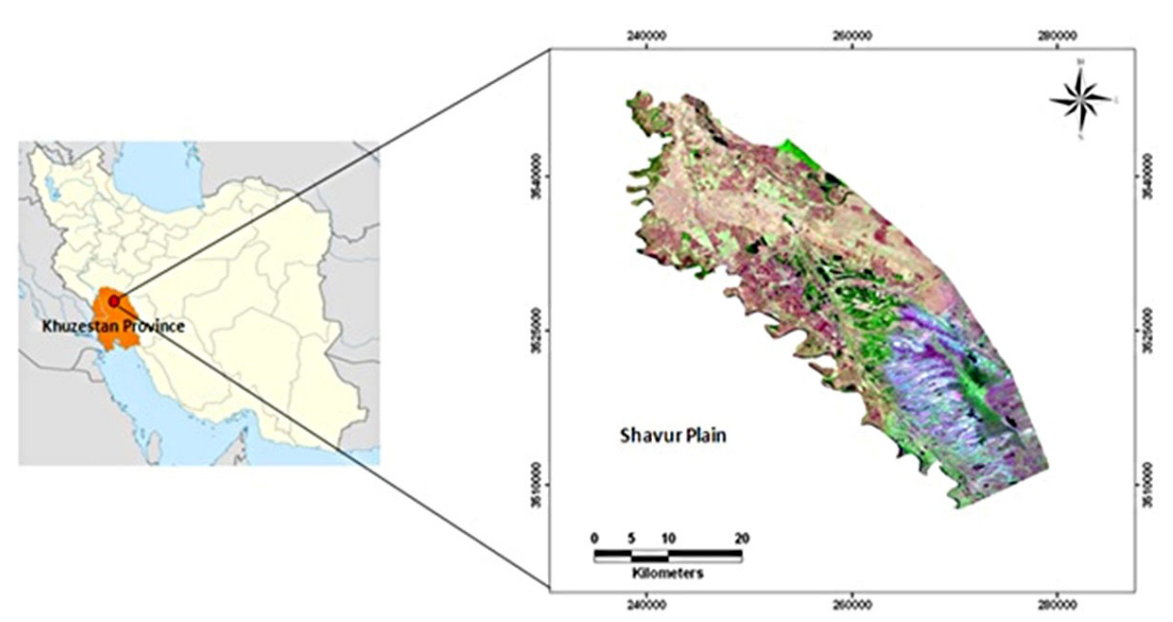

Figure 1. Location of the study area, Shavur Plain in Iran (WGS 84, UTM-Zone 38 N).

Table 1. Summary of parameters for land suitability classification in the study area.

\begin{tabular}{cccc}
\hline Parameters & & Minimum & Maximum \\
\hline $\mathrm{pH}$ & & 7.90 & 8.32 \\
\hline gypsum & 0.00 & 2.94 \\
\hline $\mathrm{CaCO}_{3}(\%)$ & 17.74 & 39.16 \\
\hline soil depth $(\mathrm{cm})$ & & 150.00 & 200.00 \\
\hline soil texture & EC $(\mathrm{ds} / \mathrm{m})$ & 7.20 & 9.75 \\
\hline \multirow{2}{*}{ salinity and alkalinity } & ESP $(\%)$ & 1.00 & 62.98 \\
& & 1.00 & 49.99 \\
\hline \multirow{2}{*}{ wetness } & water table depth $(\mathrm{cm})$ & 0.00 & 200.00 \\
& depth of segment $(\mathrm{cm})$ & 0.00 & 100.00 \\
\hline \multirow{2}{*}{ topography } & primary slope $(\%)$ & 0.00 & 3.50 \\
& secondary slope $(\%)$ & 0.00 & 1.50 \\
& micro-relief $(\mathrm{cm})$ & 0.00 & 45.00 \\
\hline
\end{tabular}

\subsection{Methodology}

The methodology of the study is summarized in six steps, as follows:

Step 1: Geospatial maps of each parameter presented in Table 1 were constructed. For this we used the geostatistical analysis and the Ordinary Kriging model was applied to the 256 sampled points.

Step 2: Based on a previous study [28-31], the following functions (Equations (1) and (2)) were determined as the best fuzzy membership functions for each parameter, and these were used to prepare fuzzy maps for all parameters. Function 1 was used for soil depth and wetness, and function 2 was used for soil texture, EC, ESP, gypsum (\%), $\mathrm{CaCO}_{3}(\%)$, topography, and $\mathrm{pH}$ values.

$$
\begin{aligned}
& \mu_{A}(X)=\left\{\begin{array}{cc}
0 & x \leq a \\
x-a / b-a & a<x<b \\
1 & x \geq b
\end{array}\right\} \\
& \mu_{A}(X)=\left\{\begin{array}{cc}
1 & x \leq a \\
b-x / b-a & a<x<b \\
0 & x \geq b
\end{array}\right\}
\end{aligned}
$$

Supposing that $X=\{x$ is a finite set of points, a fuzzy subset, $A$ subset $A$ of $X$, is defined by a function, $\mu_{A}(X)$, in the ordered pairs: $A=\left\{x, \mu_{A}(X)\right\}$ for each $x, x$ belongs to $X$. where $\mu_{A}(X)$ is 
membership function that defines the grade of membership of $x$ in A fuzzy set. The $\mu_{A}(X)$ takes values between 0 and 1 , inclusive. The value of 1 means that $x$ belongs completely to $A$, and 0 means that $x$ absolutely does not belong to the subset $A$. $A$ value between 0 and 1 indicates that, to some degree, $x$ belongs to the subset $A$. The values $a, b$ are the lower and upper limit values according to Sys's table [34].

Step 3: The AHP method was employed in order to determine the weights of assessment parameters for land suitability classification. This method is based on a pair wise comparison matrix $[43,44]$. To derive the pair wise comparison matrix, the relative importance of input parameters (Table 1) was defined by using the published reports by the Khuzestan Soil and Water Research Institute [42]. This report shows that soil salinity and alkalinity, soil wetness, $\mathrm{CaCO}_{3}$, gypsum, $\mathrm{pH}$, soil texture, soil depth and topography are the most important parameters (restriction) for the cultivation of barley in the study area, respectively. The relative importance of these parameters were assigned based on Saaty's scale (Table 2) and the pair-wise comparison matrix and the final weights for each parameter were derive (Table 3).

Table 2. Scales for pair-wise AHP comparisons [45].

\begin{tabular}{cc}
\hline Intensity of Importance & Definition \\
\hline 1 & Equal Importance \\
2 & Weak or slight \\
3 & Moderate importance \\
4 & Moderate plus \\
5 & Strong importance \\
6 & Strong plus \\
7 & Very strong or demonstrated importance \\
8 & Very, very strong \\
9 & Extreme importance \\
\hline \multirow{2}{*}{ Reciprocals of above } & If activity $\mathrm{i}$ has one of the above non-zero numbers assigned to it when \\
\end{tabular}

Table 3. Pairwise comparison matrix for land suitability for barley.

\begin{tabular}{cccccccccc}
\hline Parameters & $\begin{array}{c}\text { EC and } \\
\text { ESP }\end{array}$ & $\begin{array}{c}\text { Soil } \\
\text { Wetness }\end{array}$ & $\mathrm{CaCO}_{3}$ & Gypsum & pH & $\begin{array}{c}\text { Soil } \\
\text { Texture }\end{array}$ & $\begin{array}{c}\text { Soil } \\
\text { Depth }\end{array}$ & Topography & Weight \\
\hline EC and ESP & 1 & 2 & 3 & 4 & 5 & 6 & 7 & 8 & 0.3290 \\
soil wetness & $1 / 2$ & 1 & 2 & 3 & 4 & 5 & 6 & 7 & 0.2243 \\
CaCO 3 & $1 / 3$ & $1 / 2$ & 1 & 2 & 3 & 4 & 5 & 6 & 0.1526 \\
gypsum & $1 / 4$ & $1 / 3$ & $1 / 2$ & 1 & 2 & 3 & 4 & 5 & 0.1053 \\
pH & $1 / 5$ & $1 / 4$ & $1 / 3$ & $1 / 2$ & 1 & 2 & 3 & 4 & 0.0750 \\
soil texture & $1 / 6$ & $1 / 5$ & $1 / 4$ & $1 / 3$ & $1 / 2$ & 1 & 2 & 3 & 0.0525 \\
soil depth & $1 / 7$ & $1 / 6$ & $1 / 5$ & $1 / 4$ & $1 / 3$ & $1 / 2$ & 1 & 2 & 0.0359 \\
topography & $1 / 8$ & $1 / 7$ & $1 / 6$ & $1 / 5$ & $1 / 4$ & $1 / 3$ & $1 / 2$ & 1 & 0.0254 \\
\hline
\end{tabular}

Step 4: Finally, to compute the land suitability map of the study area, the convex combination of the raster values containing the different fuzzy parameters were calculated using the linear additive combination models [12] as in Equation (3):

$$
S I=\sum_{j=1}^{k} W_{j} \times \mu_{j(x)} \quad x \varepsilon X
$$

where the value of $S I$ is the land suitability index, $k$ is the number of parameters (Table 1$), W_{j}$ is the weight of parameter $j$, which is computed by using AHP (Table 3 ), and $\mu_{j(X)}$ is the membership grade for factor $j$. The value of $S I$ is between 0 and 1 , where a value of 0 represents totally unsuitability and 1 indicates 100\% suitability. The suitability classification was assigned as presented in Table 4, 
based on the FAO framework [1], and modified slightly in this study. Thus S1 represents that the land unit is highly suitable to barely crop production with no limitations; S2 represents that the land unit is moderately suitable with some limitations; S3 represents that the land unit is marginally suitable with severe limitations; and $\mathrm{N}$ represents that the land unit is unsuitable for barely growth.

Table 4. Land suitability classes for the barely in the study area.

\begin{tabular}{ccc}
\hline Suitability Class & Suitability Index & Definition \\
\hline S1 & $0.79-0.99$ & highly suitable \\
S2 & $0.74-0.79$ & moderately suitable \\
S3 & $0.65-0.74$ & marginally suitable \\
N & $0.10-0.65$ & unsuitable \\
\hline
\end{tabular}

Step 5: The previous approach needs a large number of land and soil parameters for land evaluation, therefore in this study three different feature selection algorithms which are most common and used methods-random search, best search and genetic methods-were used to determine the most effective parameters for land suitability classification. For each feature selection method, the most effective parameters were selected, and then weights for each parameter were re-calculated according to the AHP. Land suitability classes were calculated for all methods (datasets) using a fuzzy-AHP approach. The details of feature selection methodology are explained in the next section.

Step 6: The Kappa coefficient developed by Cohen [46], was used to assess the agreement between the standard fuzzy-AHP map and the maps obtained from the different feature selection methods. The Kappa coefficient is a measurement of the degree of agreement between two observations (maps). A Kappa value of 0 indicates that there is a poor agreement between two maps and a value of 1 indicates an almost perfect agreement. The methodology of this study is summarized in Figure 2.

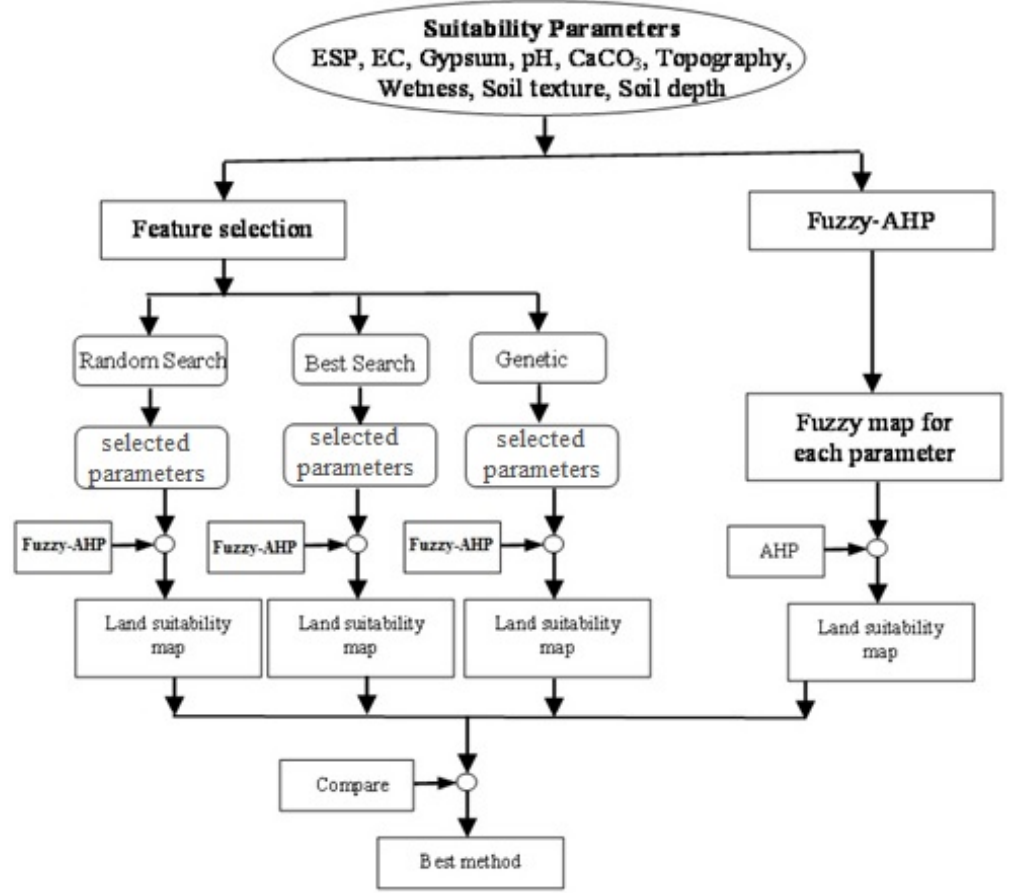

Figure 2. Overview of the methodology.

\section{Feature Selection Method}

The main idea of feature selection is to choose a subset of input variables by eliminating features with little or no predictive information. Feature selection can significantly improve the 
comprehensibility of the resulting classifier models, and it often builds a model that better generalizes to unseen points. Feature selection has been developed for decades in statistical pattern recognition [47], machine learning [48], data mining [49] and statistics [50].

Ideally, feature selection methods search through the subsets of features, and try to find the best one among the competing $2 \mathrm{~N}$ (size) candidate subsets according to some evaluation function. This procedure is exhaustive as it tries to find only the best one. There are four basic steps in a typical feature selection method, as follows:

(a) The generation procedure: this is basically a search procedure, which generates subsets of features for evaluation.

(b) The evaluation function: An evaluation function measures the goodness of a subset produced by some generation procedure, and this value is compared with the previous best. If it is found to be better, then it replaces the previous best subset.

(c) The stopping condition: Without a suitable stopping criterion, the feature selection process may run exhaustively or forever through the space of subsets. Generation procedures and evaluation functions can influence the choice of a stopping criterion. A Stopping criteria based on a generation procedure include: (i) whether a predefined number of features are selected; and (ii) whether a predefined number of iterations is reached. Stopping criteria based on an evaluation function can be: (i) whether addition (or deletion) of any feature does not produce a better subset; and (ii) whether an optimal subset according to some evaluation function is obtained. The loop continues until the stopping criterion is satisfied.

(d) The validation procedure: the validation procedure is not a part of the feature selection process itself, but a feature selection method (in practice) must be validated. It tries to test the validity of the selected subset by carrying out different tests, and comparing the results with previously established results, or with the results of competing feature selection methods, using artificial datasets, real-world datasets, or both [51].

In this research, the different feature selection methods applied were best search, genetic search and random search. A short description of each method is given in the following boxes:

Best search [52]

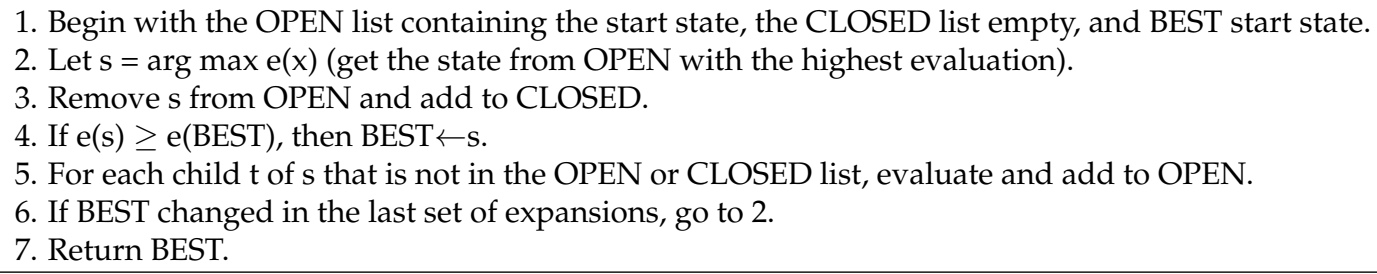

Genetic search [52]

1. Begin by randomly generating an initial population $P$.

2. Calculate $\mathrm{e}(\mathrm{x})$ for each member $\mathrm{x} \in \mathrm{P}$.

3. Define a probability distribution $p$ over the members of $P$ where $p(x) \alpha e(x)$.

4. Select two population members $x$ and $y$ with respect to $p$.

5. Apply crossover to $x$ and $y$ to produce new population members $x^{\prime}$ and $y^{\prime}$.

6. Apply mutation to $x^{\prime}$ and $y^{\prime}$.

7. Insert $\mathrm{x}^{\prime}$ and $\mathrm{y}^{\prime}$ into $\mathrm{P}^{\prime}$ (the next generation).

8. If $\left|\mathrm{P}^{\prime}\right|<|\mathrm{P}|$, go to 4 .

9. Let $\mathrm{P} \leftarrow \mathrm{P}^{\prime}$.

10. If there are more generations to process, go to 2 .

11. Return $\mathrm{x} \in \mathrm{P}$ for which $\mathrm{e}(\mathrm{x})$ is highest. 


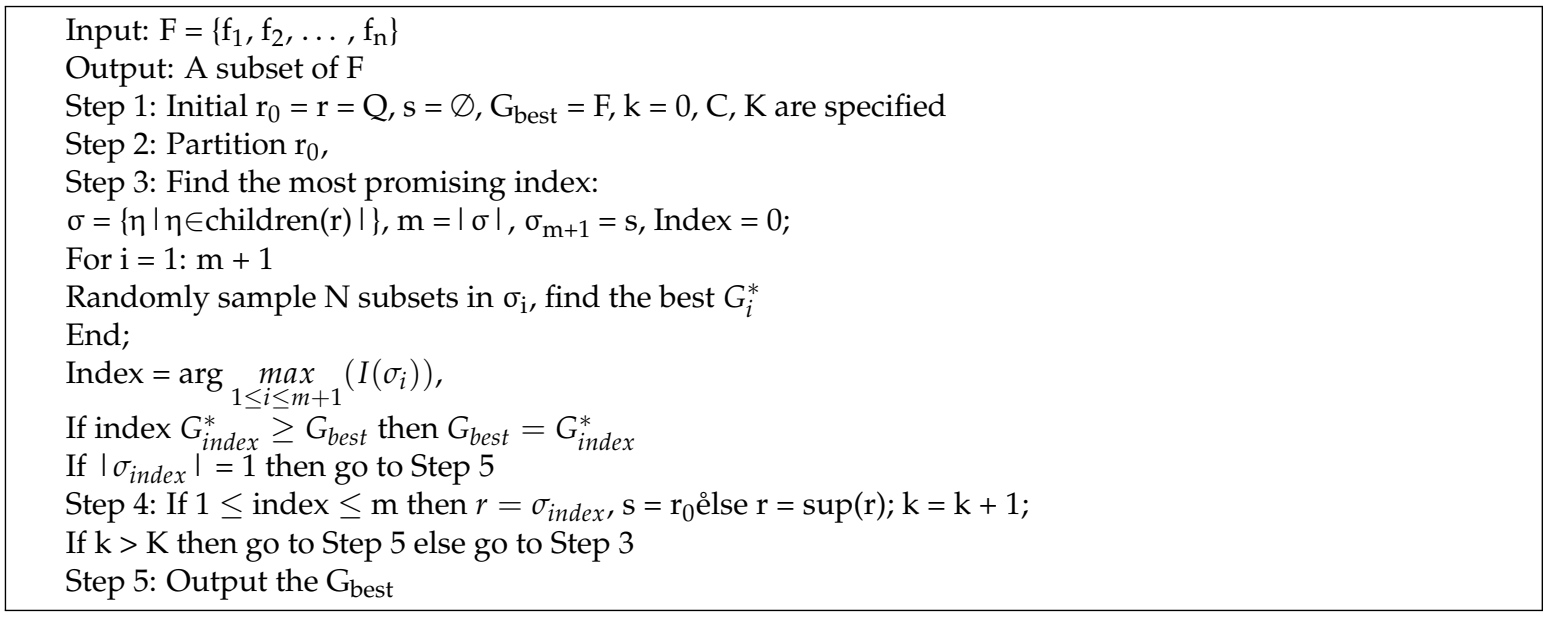

\section{Results and Discussion}

The primary fuzzy maps achieved by the appropriate fuzzy function and Kriging interpolation method for each parameter are shown in Figure 3. The land suitability map based on the fuzzy-AHP is shown in Figure 4.

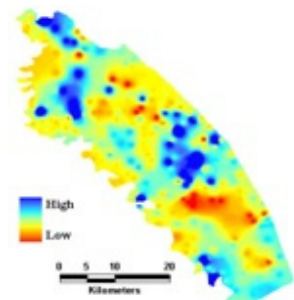

$\mathrm{CaCO3}$

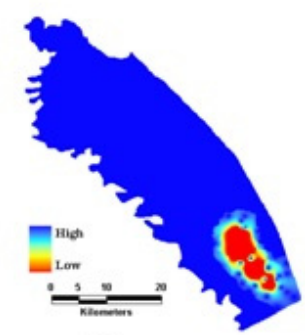

$\mathrm{pH}$

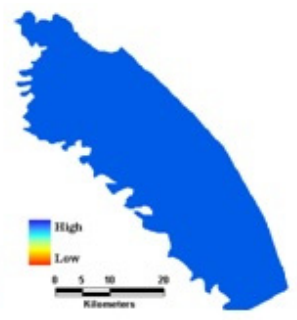

Gypsum

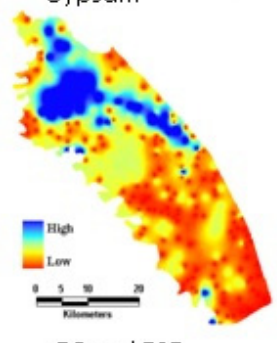

EC and ESP

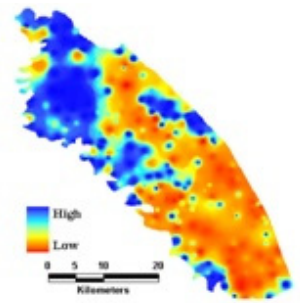

Soil texture

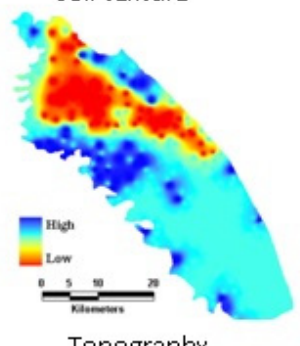

Topography

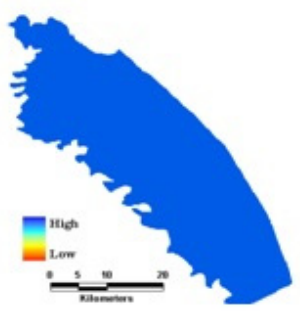

Depth of soil

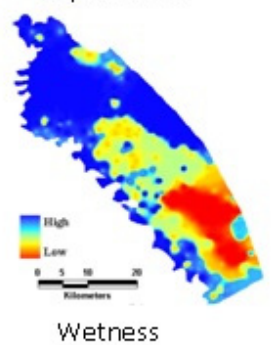

Figure 3. Fuzzy maps for each parameter.

Using the feature selection methods and applying a random search on the dataset, the variables EC, ESP, wetness and soil texture were selected as inputs for the land suitability classification. With the best search algorithm and the genetic search method, EC, ESP, gypsum and soil texture were selected (Table 5).

Table 5. The feature selection results.

\begin{tabular}{cc}
\hline Method & Selected Features \\
\hline random search & $\begin{array}{c}\text { EC and ESP } \\
\text { wetness } \\
\text { soil texture }\end{array}$ \\
\hline best search & gypsum \\
& $\begin{array}{c}\text { EC and ESP } \\
\text { soil texture }\end{array}$ \\
\hline genetic search & gypsum \\
& $\begin{array}{c}\text { EC and ESP } \\
\text { soil texture }\end{array}$ \\
\hline
\end{tabular}




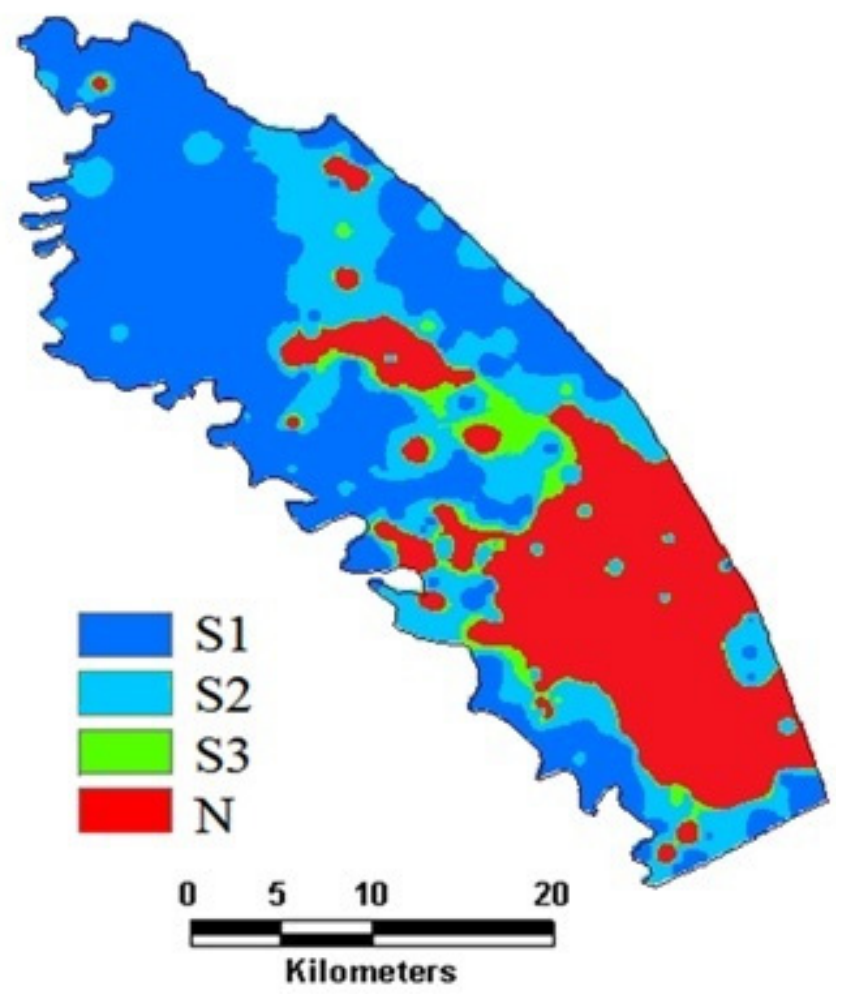

Figure 4. Land suitability map for barley using the fuzzy-AHP method (S1: high suitability, S2: moderate suitability, S3: marginal suitability, N: non-suitability).

After determining the most important parameters by different feature selection methods, the pairwise comparison matrices were calculated for the selected parameters. These weights are given in Tables 6 and 7.

Table 6. Pairwise comparison matrix using the random search.

\begin{tabular}{ccccc}
\hline Parameters & EC and ESP & Wetness & Soil Texture & Weight \\
\hline EC and ESP & 1 & 2 & 3 & 0.53 \\
wetness & $1 / 2$ & 1 & 2 & 0.3 \\
soil texture & $1 / 3$ & $1 / 2$ & 1 & 0.17 \\
\hline
\end{tabular}

Table 7. Pairwise comparison matrix using the best search and genetic search methods.

\begin{tabular}{ccccc}
\hline Parameters & EC and ESP & Gypsum & Soil Texture & Weight \\
\hline EC and ESP & 1 & 2 & 3 & 0.53 \\
gypsum & $1 / 2$ & 1 & 2 & 0.3 \\
soil texture & $1 / 3$ & $1 / 2$ & 1 & 0.17 \\
\hline
\end{tabular}

Land suitability maps for different feature selection methods are shown in Figure 5.

The value of the Kappa coefficient for the random search, best search and genetic search methods compared with the fuzzy-AHP method were calculated as $0.82,0.79$ and 0.79 , respectively. The result shows that there is a strong agreement between the standard fuzzy-AHP method and the random search method for the determination of land suitability in the study area. Figure 6 shows the results of this comparison as a map. 

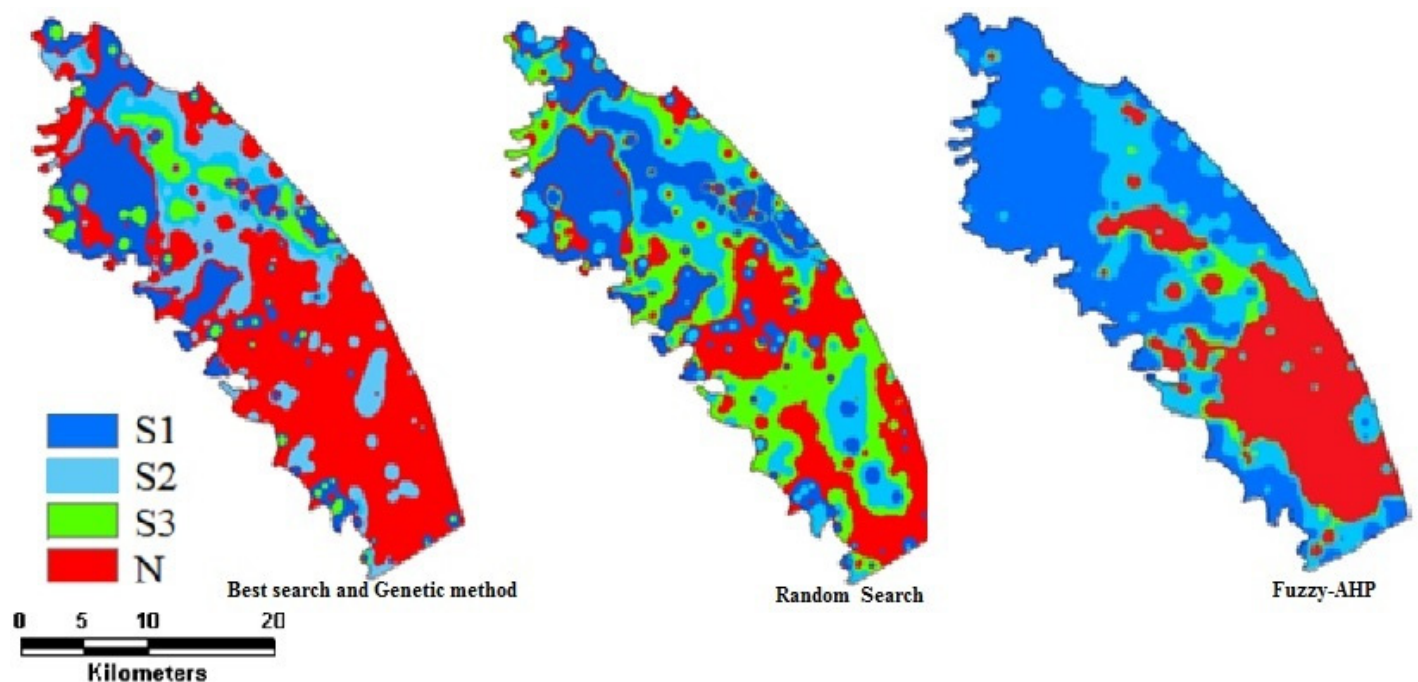

Figure 5. Land suitability maps for barley using the combined method of feature selection and fuzzy-AHP.

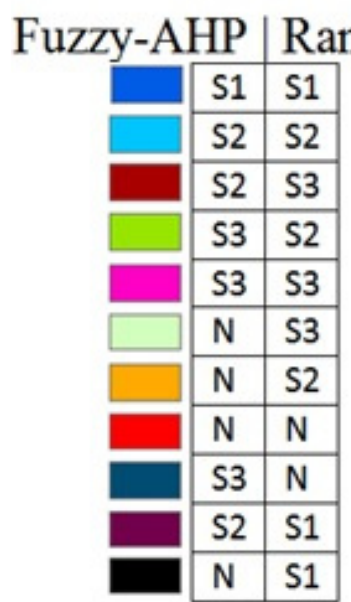
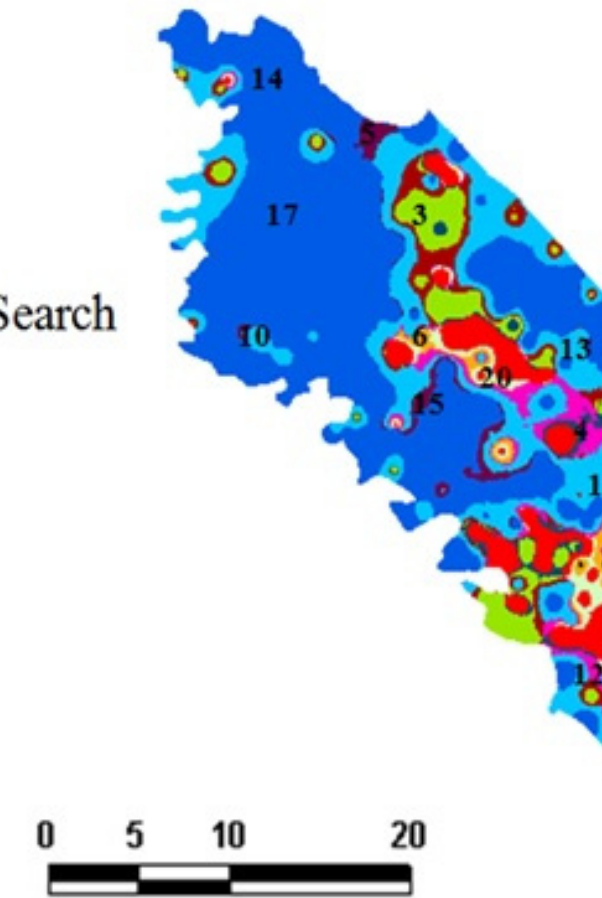

Kilometers

Figure 6. Comparison map showing correspondence between fuzzy-AHP and random search results.

The results of the random search showed $40 \%$ of the study area as highly suitable for barley (S1 class), $17 \%$ as moderately suitable (S2 class), $21 \%$ as marginally suitable (S3 class) and $22 \%$ as unsuitable (N class). The results of the fuzzy-AHP method showed $44 \%$ of the study area as highly suitable for barley (S1 class), 22\% as moderately suitable (S2 class), $4 \%$ as marginally suitable (S3 class) and $28 \%$ as unsuitable ( $\mathrm{N}$ class).

In order to better evaluate the obtained results, 20 irrigated barley fields in the study area were randomly chosen and their yields were measured at the end of the growing season. Then, based on the Table of Sys [17], the corresponding class of each field was determined and compared with the classes obtained from the fuzzy-AHP method and different feature selection algorithms. These results are given in Table 8. 
Table 8. Comparison of the results of different random search methods and standard FAO and fuzzy-AHP methods based on crop yield.

\begin{tabular}{|c|c|c|c|c|c|c|c|}
\hline Points & $\begin{array}{l}\text { Observed Yield } \\
\text { (ton/ha) }\end{array}$ & $\begin{array}{c}\text { Rate of Decrease Yield } \\
\text { Relative to Potential } \\
\text { Yield* }(\%)\end{array}$ & $\begin{array}{c}\text { Suitability } \\
\text { Classes Based on } \\
\text { the Sys'S Table }\end{array}$ & $\begin{array}{l}\text { Suitability Class } \\
\text { by Fuzzy-AHP }\end{array}$ & $\begin{array}{c}\text { Suitability Class } \\
\text { by Random } \\
\text { Search }\end{array}$ & $\begin{array}{l}\text { Suitability Class } \\
\text { by Best Search }\end{array}$ & $\begin{array}{c}\text { Suitability Class } \\
\text { by Genetic } \\
\text { Method }\end{array}$ \\
\hline 1 & 1.9 & 62 & $\mathrm{~N}$ & $\mathrm{~N}$ & $\mathrm{~N}$ & $\mathrm{~N}$ & $\mathrm{~N}$ \\
\hline 3 & 2.3 & 53.2 & S3 & S3 & $\mathrm{N}$ & S3 & S3 \\
\hline 4 & 2.6 & 47 & S3 & S3 & S3 & S3 & S3 \\
\hline 5 & 2.5 & 48.2 & S2 & S3 & S3 & S3 & S3 \\
\hline 6 & 4.6 & 7 & S1 & S1 & S1 & S1 & S1 \\
\hline 8 & 1.7 & 64.4 & $\mathrm{~N}$ & $\mathrm{~N}$ & $\mathrm{~N}$ & S3 & S3 \\
\hline 9 & 4.5 & 8.8 & S1 & S1 & S1 & S1 & $\mathrm{S} 1$ \\
\hline 10 & 4.6 & 6.6 & S1 & S1 & S1 & S2 & S2 \\
\hline 11 & 1.5 & 68.8 & $\mathrm{~N}$ & $\mathrm{~N}$ & S3 & $\mathrm{N}$ & $\mathrm{N}$ \\
\hline 12 & 4.5 & 8.8 & S1 & S1 & S1 & S1 & S1 \\
\hline 13 & 4 & 20 & S2 & S1 & S1 & S2 & S2 \\
\hline 14 & 4.7 & 6 & S1 & S1 & S1 & S2 & S2 \\
\hline 15 & 4.2 & 14.4 & S1 & S1 & $\mathrm{S} 1$ & S1 & S1 \\
\hline 16 & 4.3 & 13.6 & S1 & S1 & S1 & S1 & S1 \\
\hline 18 & 4.2 & 15.8 & $\mathrm{~S} 2$ & S1 & S1 & $\mathrm{S} 2$ & $\mathrm{~S} 2$ \\
\hline 19 & 3.4 & 31 & $\mathrm{~S} 2$ & S2 & S3 & $\mathrm{S} 2$ & $\mathrm{~S} 2$ \\
\hline 20 & 3.9 & 20.4 & S2 & S1 & S2 & S1 & S1 \\
\hline
\end{tabular}

Potential yield $=5$ ton $/$ ha. 
As shown in Table 8, there is a high agreement between the traditional results of Sys's table and the fuzzy-AHP method. With the fuzzy-AHP method, 16 of the 20 reference fields were assigned to the correct class. Also, a comparison of the classes obtained by fuzzy-AHP and different feature selection methods shows that 16, 15 and 15 selected points by random search, best search and genetic methods, respectively, were assigned to the same class selected by the original fuzzy-AHP method.

\section{Conclusions}

Recently, there has been increasing interest in methods for the evaluation of agricultural land suitability. Most methods for land suitability classification use a large number of parameters, which is time consuming and costly. In this study, the capability of different feature selection methods (best search, random search and genetic search methods) combined with the fuzzy-AHP approach as novel and potentially time and cost saving methods were evaluated for land suitability classification for the cultivation of barely. Results showed that all three methods performed well for this purpose, but the random search method performed slightly better than the other methods. Also, soil texture, wetness, EC and ESP are the most effective parameters for the determination of land suitability classification. Overall, it can be concluded that the proposed feature selection and fuzzy-AHP combined model in this study improves the prediction of important parameters for land suitability classification and provides a faster and more cost-effective approach for land suitability classification. Feature selection is itself useful, but the increasing over-fitting risk when the number of observations is insufficient and the significant computation time when the number of variables is large, are the two main weakness of this method.

Acknowledgments: The authors would like to acknowledge the Khuzestan Soil and Water Research Institute for their assistance during the study and for providing the dataset. Furthermore, we appreciate the invaluable support provided by the AuthorAid community, especially Ann Seward, for the English editing of the paper.

Author Contributions: Saeid Hamzeh and Marzieh Mokarram carried out and analyzed the data and wrote the paper. Azadeh Haratian assisted with the programing of the feature selection algorithms. Harm Bartholomeus, Arend Ligtenberg and Arnold Bregt carried out the critical revision of the manuscript.

Conflicts of Interest: The authors declare no conflict of interest.

\section{References}

1. FAO. A Framework for Land Evaluation; FAO Soils Bulletin No. 32; FAO: Rome, Italy, 1976; p. 72.

2. Sonneveld, M.P.W.; Hack-ten Broeke, M.J.D.; van Diepen, C.A.; Boogaard, H.L. Thirty years of systematic land evaluation in the Netherlands. Geoderma 2010, 156, 84-92. [CrossRef]

3. Baiocchi, V.; Lelo, K.; Polettini, A.; Pomi, R. Land suitability for waste disposal in metropolitan areas. Waste Manag. Res. 2014, 32, 707. [CrossRef] [PubMed]

4. He, Y.; Yao, Y.; Chen, Y.; Ongaro, L. Regional Land Suitability Assessment for Tree Crops Using Remote Sensing and GIS. In Proceedings of the IEEE Computer Distributed Control and Intelligent Environmental Monitoring (CDCIEM), Changsha, Hunan, China, 19-20 February 2011; pp. 354-363.

5. Prakash, T.N. Land Suitability Analysis for Agricultural Crops: A Fuzzy Multicriteria Decision Making Approach, Science in Geoinformatics; ITC: Enschede, The Netherlands, 2003; pp. 6-13.

6. Lukasheh, A.F.; Droste, R.L.; Warith, M.A. Review of expert system (ES), geographical information system (GIS), decision support system (DSS) and their application in landfill design and management. Waste Manag. Res. 2001, 19, 177-185. [CrossRef] [PubMed]

7. Abd el-Kawy, O.R.; Ismasil, H.A.; Rqd, J.K.; Suliman, A.S. A Developed GIS-based Land Evaluation Model for Agricultural Land Suitability Assessments in Arid and Semi-Arid Regions. Res. J. Agric. Biol. Sci. 2010, 6, 589-599.

8. FAO. Guidelines for Land Evaluation for Rainfed Agriculture; FAO Soils Bulletin No. 52; FAO: Rome, Italy, 1984.

9. FAO. Guidelines Land Evaluation for Irrigated Agriculture; FAO Soils Bulletin No. 55; FAO: Rome, Italy, 1985.

10. FAO. Land Evaluation: Towards A Revised Framework; Land and Water Discussion Paper No. 6; Food and Agriculture Organization of the United Nations: Rome, Italy, 2007. 
11. Kalogirou, S. Expert systems and GIS: An application of land suitability evaluation. Comput. Environ. Urban Syst. 2002, 26, 89-120. [CrossRef]

12. Malczewski, J. GIS-based land-use suitability analysis: A critical overview. Prog. Plan. 2004, 62, 53-65. [CrossRef]

13. Pan, G.; Pan, J. Research in crop land suitability analysis based on GIS. Comput. Comput. Technol. Agric. 2012, 365, 314-325.

14. Malczewski, J. GIS and Multicriteria Decision Analysis; Wiley: New York, NY, USA, 1999.

15. Ceballos Silva, A.; Lopez Blanco, J. Evaluating biophysical variables to identify suitable areas for oat in Central Mexico: a multi-criteria and GIS approach. Agric. Ecosyst. Environ. 2003, 95, 371-377. [CrossRef]

16. Abushnaf, F.F.; Spence, K.J.; Rotherham, I.D. Developing a land evaluation model for the Benghazi region in northeast Libya using a geographic information system and multi-criteria analysis. APCBEE Proc. 2013, 5 , 69-75. [CrossRef]

17. Feizizadeh, B.; Blaschke, T. Land suitability analysis for Tabriz county, Iran: A multi-criteria evaluation approach using GIS. J. Environ. Plan. Manag. 2012, 56, 1-23. [CrossRef]

18. Mendas, A.; Delali, A. Integration of multi-criteria decision analysis in GIS todevelop land suitability for agriculture: Application to durum wheat cultivation in the region of Mleta in Algeria. Comput. Electron. Agric. 2012, 83, 117-126. [CrossRef]

19. Ligtenberg, A.; Bregt, A.K.; Van Lammeren, R. Multi-actor-based land use modeling: Spatial planning using agents. Landsc. Urban Plan. 2003, 56, 21-33. [CrossRef]

20. Xiao, N.; Bennett, D.A.; Armstrong, M.P. Using evolutionary algorithms to generate alternatives for multiobjective site-search problems. Environ. Plan. A 2002, 34, 639-656. [CrossRef]

21. Mokarram, M.; Hamzeh, S.; Aminzadeh, F.; Zarei, A. Using machine learning for land suitability classification. West Afr. J. Appl. Ecol. 2016, 23, 63-73.

22. Jankowski, P.; Andrienko, N.; Andrienko, G. Map-centered exploratory approach to multiple criteria spatial decision making. Int. J. Geogr. Inf. Sci. 2001, 15, 101-127. [CrossRef]

23. Akinci, H.; Ozalp, A.Y.; Turgut, B. Agricultural land use suitability analysis using GIS and AHP technique. Comput. Electron. Agric. 2013, 97, 71-82. [CrossRef]

24. Chavez, M.D.; Berentsen, P.B.M.; Lansink, A. Assessment of criteria and farming activities for tobacco diversification using the analytical hierarchical process (AHP) technique. Agric. Syst. 2012, 111, 53-62. [CrossRef]

25. Liu, M.; Samal, A. A fuzzy clustering approach to delineate agroecozones. Ecol. Model. 2002, 149, $215-228$. [CrossRef]

26. Malczewski, J. Fuzzy screening for land suitability analysis. Geogr. Environ. Model. 2002, 6, 27-39. [CrossRef]

27. Triantafilis, J.; Ward, W.T.; McBratney, A.B. Land suitability assessment in the Namoi Valley of Australia, using a continuous model. Aust. J. Soil Res. 2001, 39, 273-289. [CrossRef]

28. Nisar Ahamed, T.R.; GopalRao, K.; Murthy, J.S.R. GIS-based fuzzy membership model for crop-land suitability analysis. Agric. Syst. 2000, 63, 79-97. [CrossRef]

29. Van Ranst, E.; Tang, H.; Groenemans, R.; Sinthurahat, S. Application of fuzzy logic to land suitability for rubber production in peninsular Thailand. Geoderma 1996, 70, 1-19. [CrossRef]

30. Hamzeh, S.; Mokarram, M.; Alavipanah, S.K. Combination of Fuzzy and AHP methods to assess land suitability for barley: Case Study of semi-arid lands in the southwest of Iran. Desert 2014, 19, 173-181.

31. Hamzeh, S.; Mokarram, M.; Naseri, A.A.; Bartholomeus, H.M.; Ligtenberg, A. Combination of Fuzzy and AHP Methods to Map Land Suitability for Barley in Comparison with the FAO Method; The 8th International Symposium, Agro Environ 2012: Wgeningen, The Netherlands, 2012.

32. Ertugrul, I.; Karakasoglu, N. Comparison of fuzzy AHP and fuzzy TOPSIS methods for facility location selection. Int. J. Adv. Manuf. Technol. 2008, 39, 783-795. [CrossRef]

33. Zhang, J.; Su, Y.; Wu, J.; Liang, H. GIS based land suitability assessment for tobacco production using AHP and fuzzy set in Shandong province of China. Comput. Electron. Agric. 2015, 114, 202-211. [CrossRef]

34. Sys, C.; Van Ranst, E.; Debaveye, J. Land Suitability, Part III: Crop requirements; International Training Center for Post Graduate Soil Scientists, Chent University: Ghent, Belgium, 1993; p. 199.

35. Alpaydin, E. Introduction to Machine Learning; MIT Press: Cambridge, MA, USA, 2010.

36. Mendonca, M. Mining Software Engineering Data: A Survey, A DACS; State-of-the-Art Report; Data and Analysis Center for Software: Rome, NY, USA, 1999. 
37. Guyon, I.; Elisseeff, A. An Introduction to Variable and Feature Selection. J. Mach. Learn. Res. 2003, 3, 1157-1182.

38. Besalatpour, A.A.; Ayoubi, S.; Hajabbasi, M.A.; Gharipour, A.; Yousefian Jazi, A. Feature selection using parallel genetic algorithm for the prediction of geometric mean diameter of soil aggregates by machine learning methods. Arid Land Res. Manag. 2014, 28, 383-394. [CrossRef]

39. Behrens, T.; Zhu, A.X.; Schmidt, K.; Scholten, T. Multi-scale digital terrain analysis and feature selection for digital soil mapping. Geoderma 2010, 155, 175-185. [CrossRef]

40. Shi, T.; Chen, Y.; Liu, H.; Wang, J.; Wu, G. Soil organic carbon content estimation with laboratory-based visible-near-infrared reflectance spectroscopy: Feature selection. Appl. Spectrosc. 2014, 68, 831-837. [CrossRef] [PubMed]

41. Mokarram, M.; Hamzeh, S.; Haratian Nejady, A.; Bartholomeus, H.M.; Bregt, A. Feature Selection for Land Suitability Evaluation in Combination with the Fuzzy-AHP Method; The 8th International Symposium, Agro Environ 2012: Wgeningen, The Netherlands, 2012.

42. Khuzestan Soil and Water Research Institute. Shavur Soil and Water Project Report; Khuzestan Soil and Water Research Institute: Khuzestan, Iran, 2009.

43. Saaty, T.L. A scaling method for priorities in hierarchical structure. J. Math. Psychol. 1977, 15, 34-39. [CrossRef]

44. Saaty, T.L. The Analytic Hierarchy Process: Planning, Priority Setting, Resource Allocation; McGraw-Hill International: New York, NY, USA, 1980.

45. Saaty, T.L.; Vargas, L.G. Prediction, Projection and Forecasting; Kluwer Academic Publisher: Dordrecht, The Netherlands, 1991; p. 251.

46. Cohen, J. Coefficient of agreement for nominal scales. Educ. Psychol. Meas. 1960, 20, 37-46. [CrossRef]

47. Mitra, P.; Murthy, C.A.; Pal, S.K. Unsupervised feature selection using feature similarity. IEEE Trans. Pattern Anal. Mach. Intell. 2002, 24, 301-312. [CrossRef]

48. Robnik-Sikonja, M.; Kononenko, I. Theoretical and empirical analysis of ReliefF and RReliefF. Mach. Learn. 2003, 53, 23-69. [CrossRef]

49. Dash, M.; Choi, K.; Scheuermann, P.; Liu, H. Feature selection for clustering-A filter solution. In Proceedings of the Second International Conference on Data Mining, Maebashi, Japan, 9-12 December 2002; pp. 115-122.

50. Miller, A. Subset Selection in Regression, 2nd ed.; Chapman \& Hall/CRC: London, UK, 2002.

51. Dash, M.; Liub, H. Consistency-based search in feature selection Elsevier. Artif. Intell. 2003, 151, $155-176$. [CrossRef]

52. Hall, M.A. Correlation-based Feature Selection for Machine Learning. Ph.D. Thesis, Hamilton, New Zealand, 1999. p. 198.

53. Li, X.; Wang, S.; Dong, Z.Y. (Eds.) The Application of Adaptive Partitioned Random Search in Feature Selection Problem. In Advanced Data Mining and Applications; Springer Berlin: Heidelberg, Germany, 2005; pp. 307-314.

(C) 2016 by the authors; licensee MDPI, Basel, Switzerland. This article is an open access article distributed under the terms and conditions of the Creative Commons Attribution (CC-BY) license (http://creativecommons.org/licenses/by/4.0/). 